\title{
Direct Molecular Fishing of New Protein Partners for Human Thromboxane Synthase
}

\author{
A. V. Svirid', P. V. Ershov², E. O. Yablokov², L. A. Kaluzhskiy², Yu. V. Mezentsev²*, \\ A. V. Florinskaya², T. A. Sushko1,3, N. V. Strushkevich1', A. A. Gilep1, S. A. Usanov¹, \\ A. E. Medvedev², A. S. Ivanov² \\ ${ }^{1}$ Institute of Bioorganic Chemistry, National Academy of Sciences of Belarus, Akad. Kuprevicha Str. \\ 5/2, Minsk, 220141, Belarus \\ ${ }^{2}$ Institute of Biomedical Chemistry, Pogodinskaya Street 10, bldg. 8, Moscow, 119121, Russia \\ ${ }^{3}$ Department of Bioengineering, School of Engineering, The University of Tokyo, Tokyo, 108-8639, \\ Japan \\ *E-mail: yu.mezentsev@gmail.com \\ Received: April 20, 2017; in final form October 11, 2017 \\ Copyright $\odot 2017$ Park-media, Ltd. This is an open access article distributed under the Creative Commons Attribution License, which permits \\ unrestricted use, distribution, and reproduction in any medium, provided the original work is properly cited.
}

\begin{abstract}
Thromboxane synthase (TBXAS1) catalyzes the isomerization reaction of prostaglandin $\mathbf{H}_{2}$ producing thromboxane $A_{2}$, the autocrine and paracrine factor in many cell types. A high activity and metastability by these arachidonic acid derivatives suggests the existence of supramolecular structures that are involved in the regulation of the biosynthesis and directed translocation of thromboxane to the receptor. The objective of this study was to identify TBXAS1 protein partners from human liver tissue lysate using a complex approach based on the direct molecular fishing technique, LC-MS/MS protein identification, and protein-protein interaction validation by surface plasmon resonance (SPR). As a result, 12 potential TBXAS1 protein partners were identified, including the components regulating cytoskeleton organization (BBIP1 and ANKMY1), components of the coagulation cascade of human blood (SERPINA1, SERPINA3, APOH, FGA, and FN1), and the enzyme involved in the metabolism of xenobiotics and endogenous bioregulators (CYP2E1). SPR validation on the Biacore 3000 biosensor confirmed the effectiveness of the interaction between CYP2E1 (the enzyme that converts prostaglandin $\mathrm{H}_{2}$ to $12-\mathrm{HHT} /$ thromboxane $\mathrm{A}_{2}$ proantagonist $)$ and TBXAS1 $\left(K_{\mathrm{d}}=(4.3 \pm 0.4) \times 10^{-7} \mathrm{M}\right)$. Importantly, the TBXAS1 - CYP2E1 complex formation increases fivefold in the presence of isatin (indole-2,3-dione, a low-molecular nonpeptide endogenous bioregulator, a product of CYP2E1). These results suggest that the interaction between these hemoproteins is important in the regulation of the biosynthesis of eicosanoids.

KEYWORDS Thromboxane synthase (CYP5A1, TBXAS1), cytochrome P450, surface plasmon resonance, direct molecular fishing, protein partners, isatin.

ABBREVIATIONS Protein-protein interaction (PPI), surface plasmon resonance (SPR), association rate constant $\left(k_{\text {on }}\right)$, dissociation rate constant $\left(k_{\text {off }}\right)$, equilibrium dissociation constant $\left(K_{d}\right)$.
\end{abstract}

\section{INTRODUCTION}

Human thromboxane synthase (TBXAS1) belongs to the cytochrome P450 superfamily (CYP5A1). However, it functions differently from "classical" cytochromes $\mathrm{P} 450$, which catalyze various monooxygenase reactions, involving redox partners as the electron donors [1]. TBXAS1 catalyzes the reaction of prostaglandin $\mathrm{H}_{2}$ $\left(\mathrm{PGH}_{2}\right)$ isomerization, which requires no redox partners and produces thromboxane $\mathrm{A}_{2}\left(\mathrm{TXA}_{2}\right)[2]$. The latter acts as a paracrine and autocrine regulator and is an important mediator of platelet aggregation and contraction of blood vessels, which contributes to increase in blood pressure.
Apart from $\mathrm{PGH}_{2}$ isomerization, TBXAS1 catalyzes the alternative $\mathrm{PGH}_{2}$ transformation reaction, resulting in its cleavage to 12 -hydroxy-5,8,10-heptatrienic acid (12-HHT) and malondialdehyde (MDA) [3]. There is currently no accurate information on the functional role of MDA and 12-HHT. MDA can form adducts with the protein amino groups or polar groups of phospholipids and thus plays a role in the molecular mechanisms of atherosclerosis, cancer, and some genetic diseases [4, 5]. 12-HHT and its metabolites can block the action of leukotriene receptors and act as a partial $\mathrm{TXA}_{2}$ antagonist by enhancing the synthesis of prostacyclin and antagonizing the thromboxane receptor (TXAR) $[6,7]$. It 
is possible that TBXAS1 also performs other functions: catalyze monooxygenase reactions characteristic of cytochrome $\mathrm{P} 450$ and involving redox partners.

TBXAS1 was first isolated from human platelets [3] and pig lungs [8]. TBXAS1 is mostly synthesized in prothrombocytes and monocyte precursor hematopoietic stem cells, leukocytes, and macrophages, where TXA is involved in the regulation of cell differentiation [9]. Synthesis of TBXAS1 was also detected in the cells of lungs, kidneys, the stomach, intestine, spleen, thymus, pancreas, and the liver [10]. TXAR, which belongs to the class of G-protein-coupled receptors (GPCRs), is expressed in many tissues (lung, spleen, liver, uterus, placenta, aorta, heart muscle, intestine, thymus, kidney, brain, and spinal cord) [11]. This may be indicative of other possible functions of TBXAS1 or the versatility of the mechanisms underlying its basic function.

One approach to elucidating the unknown functions of a protein is based on studying its interactions with other proteins whose functions are known [12]. This approach is based on the concept that the functions of the interacting protein partners must be either interrelated or form a single protein complex that performs interrelated functions. The substrate and product of the reaction catalyzed by TBXAS1 are extremely short-living and active lipophilic molecules, whose diffuse transport is complicated, while the $\mathrm{TXA}_{2}$ receptor is located on the outside of the plasma membrane. This suggests the existence of a specific transport mechanism or, most likely, an interaction with the associated protein complexes responsible for the transportation of these short-living compounds.

To date, information on experimental validation of protein-protein interactions (PPI) involving TBXAS1 remains scarse. The BioGRID database includes only two records of identified PPIs involving TBXAS1 (https://thebiogrid.org/112778/summary/homo-sapiens/tbxas 1.html?sort=bait): (1) interaction with an eukaryotic elongation factor $1 \alpha-2$ (EEF1A2) citing unpublished data [13], and (2) interaction with ubiquitin C (UBC) [14]. It is most likely that both these interactions are nonspecific, since the same BioGRID database includes records of 132 potential interactions of EEF1A2 with 124 partners and 2,332 interaction of UBC with 1,440 partners. In 2016, Meling D.D. cited in the abstract of his dissertation (Protein-protein interactions and mechanistic insights for CYP2J2 and TBXAS1) unpublished data on interaction between TBXAS1 and cytochrome $\mathrm{P} 450$ reductase (CPR) (http://hdl.handle. net/2142/90774), which undoubtedly may be functionally significant, since CPR is a known protein partner of the microsomal cytochromes $\mathrm{P} 450$.

Previously, we developed an integrated approach to the discovery of novel protein partners interacting with a target protein which is based on the use of direct molecular fishing on the affinity sorbent with the immobilized target protein (or peptide) as a ligand, mass spectrometric identification of the isolated proteins, and validation of the potential PPIs by surface plasmon resonance (SPR) [15-17].

The objective of the present study was to search for novel potential TBXAS1 protein partners in the human liver tissue lysate using this approach. As a result, 12 potential TBXAS1 protein partners were isolated on the affinity column with immobilized TBXAS1 using a LC-MS/MS-analysis, one of which was cytochrome P450 (CYP2E1). SPR validation confirmed its interaction with TBXAS1 immobilized on the optical chip and identified another potential protein partner (CYP11B2). SPR experiments with five control cytochromes P450 (CYP2C19, CYP11A1, CYP11B1, CYP3A4, CYP3A5) were negative, indicating the high specificity of the detected PPIs. Since CYP2E1 is involved in the metabolism of various indole derivatives [18], we further investigated the possible influence of the well-known endogenous bioregulator isatin (indole-2,3-dione) [1922 ] on the interaction of CYP2E1 and CYP11B2 with TBXAS1. We found that isatin results in a fivefold increase in affinity of the TBXAS1 - CYP2E1 interaction and does not affect the TBXAS1 - CYP11B2 interaction.

\section{EXPERIMENTAL}

\section{Protein preparations}

Highly purified ( $>95 \%$ according to denaturing polyacrylamide gel electrophoresis (SDS-PAGE)) preparations of the recombinant proteins, TBXAS1, cytochromes P450 (limonene 6-monooxygenase (CYP2C19), steroid-20,22-lyase (CYP11A1), steroid-11ß-hydroxylase (CYP11V1), aldosterone synthase (CYP11B2), taurochenodeoxycholate- $6 \alpha$-monooxygenase (CYP3A4), cyclic hydrocarbon hydroxylase (CYP3A5), 4-nitrophenol-2-hydroxylase (CYP2E1), microsomal cytochrome $\mathrm{b}_{5}$ (CYB5A), NADPH-cytochrome-P450-reductase (CPR), NADPH-adrenodoxin reductase (ADR), adrenodoxin (ADX), and ferrochelatase (FECH), SMAD4, RAB27B) were prepared at the Institute of Bioorganic Chemistry (Republic of Belarus) by molecular cloning and heterologous expression in a bacterial system (E. coli), followed by purification using metal-affinity and ion exchange chromatography $[23,24]$. The preparation of retinol-binding protein 4 (RBP4) was obtained from Cayman chemical (USA).

\section{Human liver tissue lysate}

Human liver tissue samples were obtained from the ILSbio LLC (www.ilsbio.com). The lysate was prepared 
by homogenization of a 100-mg tissue liver sample in a Potter mortar with $1 \mathrm{~mL}$ of the CellLytic Mammalian Tissue Lysis/Extraction Reagent (Sigma, USA) and $10 \mu \mathrm{L}$ of a protease inhibitor cocktail (Sigma, USA). After centrifugation at $13,400 \mathrm{~g}$ and $4^{\circ} \mathrm{C}$ for $25 \mathrm{~min}$, the supernatant was collected, glycerol was added to a final concentration of $25 \%$, and the resulting solution was stored at $-80^{\circ} \mathrm{C}$. The total protein concentration in the lysate samples was $10-20 \mathrm{mg} / \mathrm{mL}$, as determined spectrophotometrically using a Bradford assay.

\section{Direct molecular fishing}

An affinity sorbent with covalently immobilized TBXAS1 as the bait protein was prepared by covalent protein binding to $\mathrm{CNBr}$-Sepharose 4B (GE Healthcare, USA) according to the manufacturer's protocol. It was found that the $0.5 \mathrm{mg} / 1 \mathrm{~g}$ protein to sorbent ratio was optimal for binding of the used TBXAS1 preparation to the sorbent. The remaining active groups of the sorbent were inactivated by incubation in a buffer containing $100 \mathrm{mM}$ Tris-HCl (pH 7.4) and $150 \mathrm{mM} \mathrm{NaCl}$. Direct molecular fishing was carried out in the original microcolumn (volume $200 \mu \mathrm{L}$ ) filled with the affinity sorbent. In the control experiments, a similar microcolumn filled with "empty" (no bait protein) inactivated CNBr-Sepharose 4B was used. HBS-EP+ buffer (10 mM HEPES (pH 7.4), $150 \mathrm{mM} \mathrm{NaCl}, 3 \mathrm{mM}$ EDTA, $0.05 \%$ Tween 20) passed through the microcolumn at a flow rate of $50 \mu \mathrm{L} / \mathrm{min}$ at $15^{\circ} \mathrm{C}$ was used as a running buffer. Affinity isolation of the TBXAS1 protein partners was carried out by passing $2 \mathrm{~mL}$ of lysate $(0.5 \mathrm{mg} / \mathrm{mL}$ of protein) twofold diluted with the running buffer through the column for 80 minutes using the 10 AKTA Purifier (GE Healthcare, USA) system. Proteins from the lysate bound to the sorbent were eluted with $4 \% \mathrm{HCOOH}(\mathrm{pH} 2.5)$ at a flow rate of $50 \mu \mathrm{L} / \mathrm{min}$ for $100 \mathrm{~min}$. The total protein content in the eluates determined by the Bradford assay was $25-35 \mu \mathrm{g} / \mathrm{mL}$ (average value $30 \mu \mathrm{g} / \mathrm{mL}$ ). The experiments on the affinity isolation of potential TBXAS1 protein partners were repeated in triplicates.

\section{LC-MS/MS-analysis}

Special sample preparation was used for the mass-spectrometric identification of the proteins. An aliquot containing $30 \mu \mathrm{g}$ of total protein was sampled from each chromatographic fraction and subjected to the standard trypsinolysis procedure with preliminary reduction and alkylation of the sulfhydryl groups of the proteins. All procedures were carried out in Vivaspin 500 Centrifugal Concentrators, $10 \mathrm{kDa} \mathrm{MWCO}$ (GE Healthcare, USA) using the FASP method [25]. A lyophilized trypsin preparation obtained from porcine pancreas (activity $15600 \mathrm{IU} / \mathrm{mg}$, V5111, Promega, USA) was used for trypsin digestion of the proteins.
Mass-spectrometric analysis of the samples was carried out in three technical replicates using a Agilent 1200 chromatograph and Agilent 6300 mass-detector with Ion Trap LC/MS (Agilent Technologies, USA). Peptides were separated using a reversed-phase HPLC-column ZORBAX Extend-C18 $(2.1 \times 150 \mathrm{~mm}$, $1.8 \mu \mathrm{m}$ ) (Agilent Technologies, USA) in a gradient of solvent A ( $0.2 \%$ formic acid in water) and Solvent B ( $0.2 \%$ formic acid in acetonitrile) for $55 \mathrm{~min}$ at a flow rate of $350 \mu \mathrm{L} / \mathrm{min}$. The sample volume applied to the column was $15 \mu \mathrm{L}(\sim 7-8 \mathrm{mg}$ of material). The gradient was as follows: from 0 to $20 \%$ of solvent B in 5 minutes, from 20 to $80 \%$ in 40 minutes, from 80 to $95 \%$ in $5 \mathrm{~min}$, and $95 \%$ for $5 \mathrm{~min}$. Column temperature was $50^{\circ} \mathrm{C}$. Mass spectra were acquired in the positive ionization mode (APESI-ionization) with the following parameters: gas temperature $400^{\circ} \mathrm{C}$, gas flow rate $9 \mathrm{~L} / \mathrm{min}$, capillary voltage $2 \mathrm{kV}$, and fragmentor voltage $360 \mathrm{~V}$. The mass analyzer was operated in the auto-MS/MS-mode with the following parameters: $\mathrm{m} / \mathrm{z}$ range from 50 to 2200 $\mathrm{m} / \mathrm{z}$, fragmentation energy was calculated according to the following formulas: $(3.1(\mathrm{~m} / \mathrm{z}) / 100+1.0) \mathrm{V}$ for $\mathrm{z}=2$ and $(3.6(\mathrm{~m} / \mathrm{z}) / 100-4.8) \mathrm{V}$ for $\mathrm{z} \geq 3$. The proteins were identified using the Mascot software (www.matrixscience.com) and SwissProt database (www.uniprot. org). The following search parameters were used: proteolytic enzyme trypsin, acceptable mass deviation of monoisotopic peptides $\pm 2.6 \mathrm{Da}$, acceptable MS/MS deviation $\pm 0.6 \mathrm{Da}$, acceptable number of omitted trypsin cleavage sites is 2 , variable modification - "oxidized methionine," and fixed modifications - "carbamidomethyl." The resulting list of reliably detected proteins included only those proteins which were identified in three technical replicates with a significance of 0.01 and Mascot Score $>50$.

\section{Surface plasmon resonance (SPR)}

PPIs were analyzed on the four-channel optical biosensor Biacore 3000 (GE Healthcare, USA), whose operation is based on the surface plasmon resonance effect controlled by the Biacore Software v. 1.0. Biosensor signals were recorded in resonance units, $R U$ (1 RU corresponds to binding of about $1 \mathrm{pg}$ of the protein on the optical chip surface). The values of the equilibrium dissociation constants $\left(K_{\mathrm{d}}\right)$, association rate constants $\left(k_{\text {on }}\right)$, and dissociation rate constants $\left(k_{\text {off }}\right)$ of the complexes were calculated using the BiaEvaluation v. 4.1 software package.

TBXAS1 was immobilized by the formation of covalent bonds between the carboxyl groups on the surface of the optical chip CM5 and the free amino groups of the protein. For this purpose, we used the Amine Coupling Kit (GE Healthcare, USA). The TBXAS1 sample $(50 \mu \mathrm{g} / \mathrm{mL})$ in $10 \mathrm{mM}$ acetate buffer ( $\mathrm{pH} 5.0)$ was inject- 


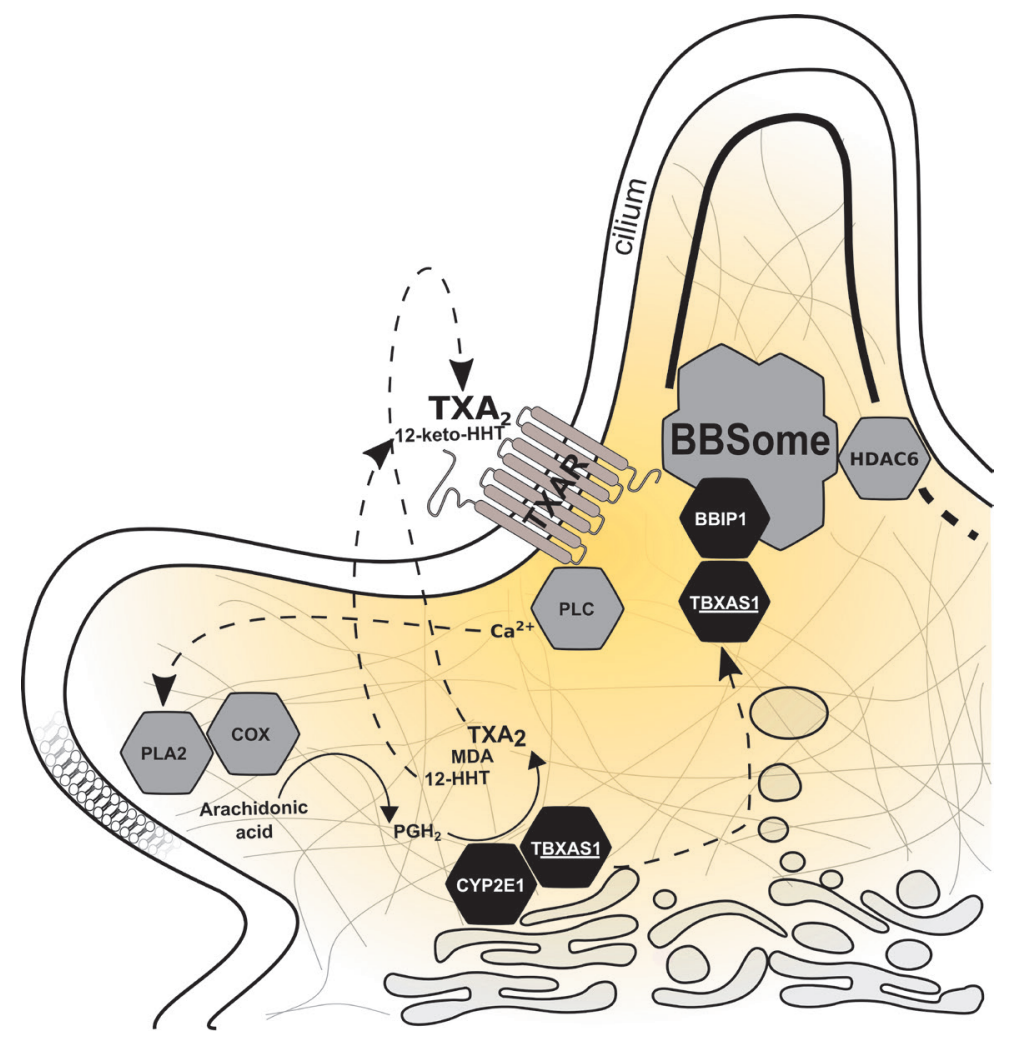

Fig. 1. Schematic representation of TXA, biosynthesis supplemented by our experimental results. PLC - phospholipase C, PLA2 - phospholipase $A_{2}, C O X$ - cyclooxygenase. Biosynthesis of $\mathrm{TX}_{2}$ begins with the release of arachidonic acid from membrane phospholipids assisted by PLA2. Then, COX catalyzes the transformation of arachidonic acid into prostaglandin $\mathrm{H}_{2}$, which is then metabolized by TBXAS1 to form TXA, $12-\mathrm{HHT}$, and MDA. At the same time, prostaglandin $\mathrm{H}_{2}$ is transformed by CYP2E1 to $12-\mathrm{HHT}$ and MDA. TXA binding to TXAR causes signal transmission via the inositol phosphate pathway with PLC activation and mobilization of intracellular $\mathrm{Ca}^{2+}$, which has a stimulating effect on PLA2. Further, $12-\mathrm{HHT}$ is metabolized by 15 -hydroxyprostaglandin dehydrogenase to form 12-keto-HHT, which has a partial antagonistic effect on TXAR. TBXAS1 also presumably interacts with BBIP1, which is a component of the protein transport complex of cilia (BBSome). BBIP1 can influence the stability of the microtubulin cytoskeleton, indirectly inhibiting HDAC6 (microtubule deacetylase). ed at a flow rate of $5 \mu \mathrm{L} / \mathrm{min}$ for $20 \mathrm{~min}$. The TBXAS1 immobilization level in the working channel of the optical biosensor averaged 7,500 RU $\left(7.5 \mathrm{ng} / \mathrm{mm}^{2}\right)$.

Interactions of test proteins with the immobilized TBXAS1 were recorded in real time mode while injecting protein samples at a concentration ranging from $50 \mathrm{nM}$ to $5 \mu \mathrm{M}$ through the control channel (without the protein) and then through the channel with immobilized TBXAS1 for $10 \mathrm{~min}$ at a flow rate of $5 \mu \mathrm{L} / \mathrm{min}$. Each measurement was followed by a regeneration of the optical chip surface by injecting buffer containing $2 \mathrm{M} \mathrm{NaCl}$ and $0.4 \% \mathrm{CHAPS}$ for $30 \mathrm{~s}$ at a flow rate of $20 \mu \mathrm{L} / \mathrm{min}$. All measurements were performed at least 4 times, which provided adequate accuracy and reproducibility (CV value was less than $10 \%$ ). In the experiments assessing the possible impact of nonpeptide low-molecular-weight endogenous bioregulator isatin (2,3-dioxoindole) on PPIs involving TBXAS1, isatin was added to the samples of analyzed proteins at a final concentration of $100 \mu \mathrm{M}$ and the mixture was incubated for $15 \mathrm{~min}$.

\section{RESULTS AND DISCUSSION}

An integrated approach based on direct molecular fishing on an affinity sorbent with a $4 \mathrm{~B}$ target protein immobilized on CNBr-Sepharose, mass-spectrometric identification of isolated proteins, and validation of PPIs with SPR enables the isolation and identification of 12 potential TBXAS1 protein partners from the lysates of human liver tissue (Table). To date, the scientific literature still provides no information on the interaction between these proteins and TBXAS1. However, some assumptions about their possible functional relationship with TBXAS1 can be made. For example, the BBIP1 protein (BBSome component of the transport protein complex of cilia) is involved in the regulation of cellular cytoskeleton stability [26, 27]. Information on ANKIMY1 is available only at the transcript level. However, its structure includes ankyrin repeats, which form one of the most common interfaces for PPIs. These repeats were found in proteins characterized by various functions [28]. Based on this fact, we assumed that ankyrin repeats of ANKMY1 can specifically recognize certain structural motifs of TBXAS1, facilitating interaction between these proteins.

However, it should be noted that proteins identified by direct molecular fishing can only be considered as potential protein partners of TBXAS1, since not only real partner proteins, but also simultaneously "fished" extraneous proteins composing micelles or supramolecular complexes may be isolated from the lysate due to the features of this techniques [17]. Among our "fished" proteins (table), these are SERPINA1, SERPINA3, $\mathrm{APOH}, \mathrm{FGA}$, and FN1, which are involved in the blood 


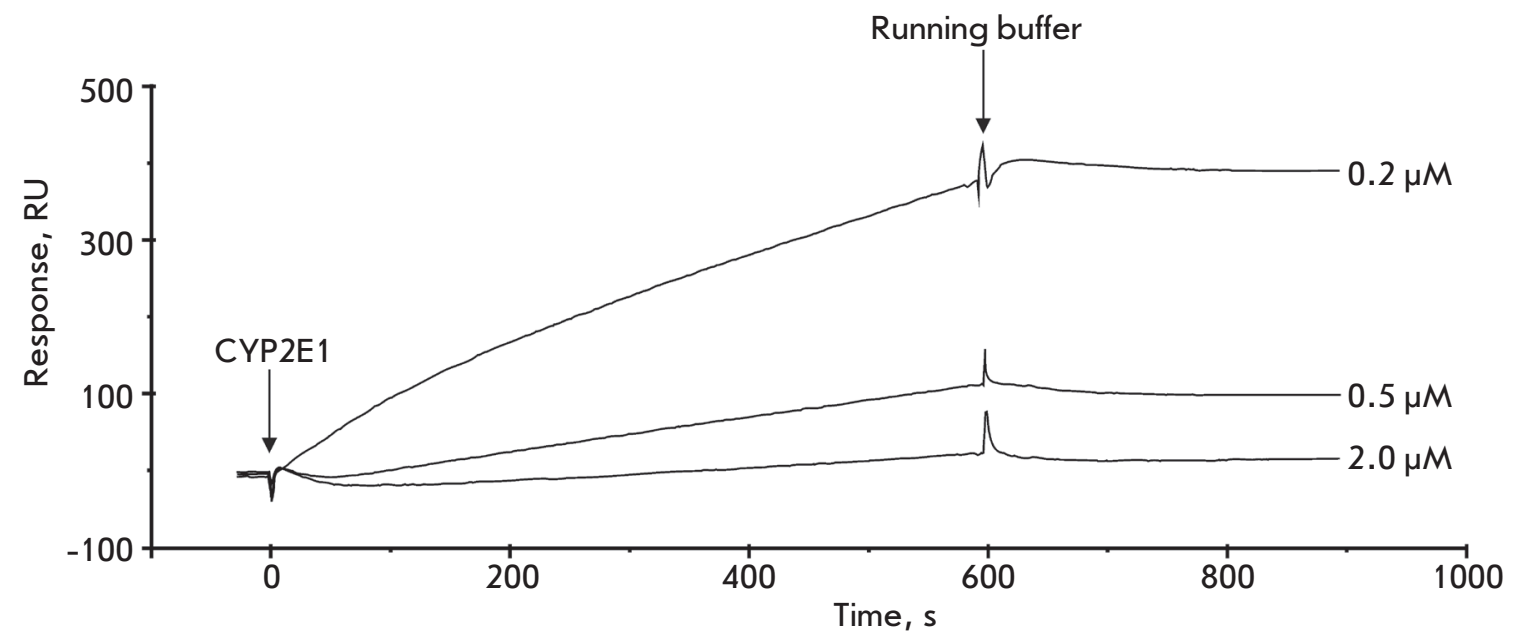

Fig. 2. Typical sensorgrams of the interaction between various concentrations of CYP2E1 and TBXAS1 immobilized on a CM5 optical chip
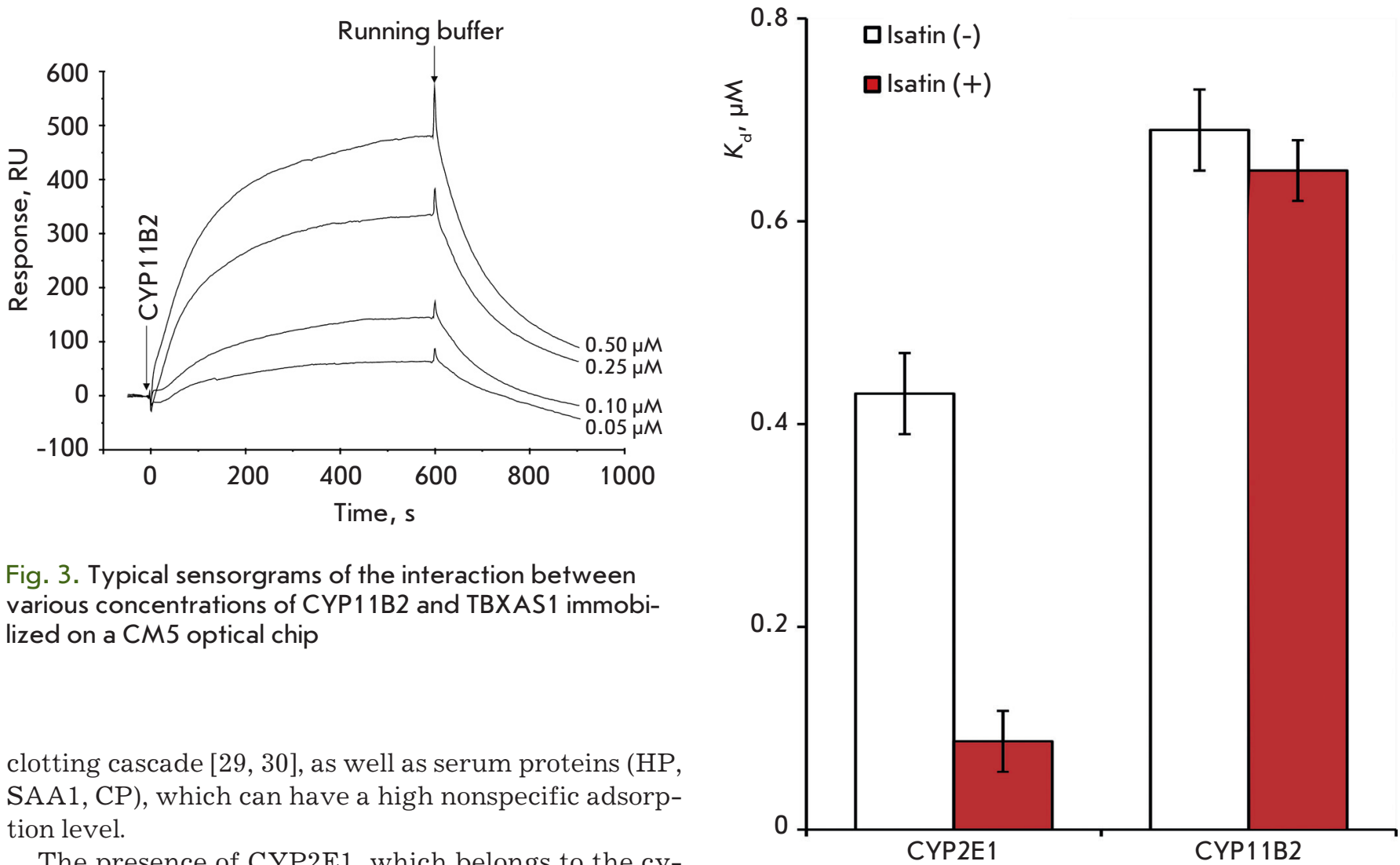

Fig. 3. Typical sensorgrams of the interaction between various concentrations of CYP11B2 and TBXAS1 immobilized on a CM5 optical chip

clotting cascade [29, 30], as well as serum proteins (HP, SAA1, CP), which can have a high nonspecific adsorption level.

The presence of CYP2E1, which belongs to the cytochromes P450 superfamily, in the list of "fished" proteins is of particular interest. A functional relationship between CYP2E1 and TBXAS1 may be important in the context of the complementary enzymatic conversion reactions of common substrates. As it is known, CYP2E1 is characterized by broad substrate specificity and a broad tissue localization profile, including the liver [31]. For example, CYP2E1 can oxidize arachidonic acid (via $\omega$-1-hydroxylation) and prostaglandin $\mathrm{H}_{2}$ [32] to form side metabolites, which, in turn, are formed in the prostaglandin $\mathrm{H}_{2}$ to thromboxane $\mathrm{A}_{2}$ isomerization reactions. 12 -keto-HHT is a further metabolite of

Fig. 4. Diagram representation of equilibrium dissociation constant $\left(K_{d}\right)$ values of the TBXAS1 . CYP2E1 and TBXAS - CYP11B2 complexes in the absence and presence of $100 \mu M$ of isatin; $M \pm m, n=3$

one of the reaction products and can influence $\mathrm{TXA}_{2}$ by increasing prostacyclin production and antagonistic action on TXAR [4, 5]. Therefore, colocalization of TBXAS1, synthesizing thromboxane $\mathrm{A}_{2}$, and CYP2E1 could serve as an additional mechanism regulating the effectiveness of enzymatic conversion of common sub- 
Mass-spectrometric identification of the proteins in eluates from chromatographic microcolumns filled with an affinity sorbent

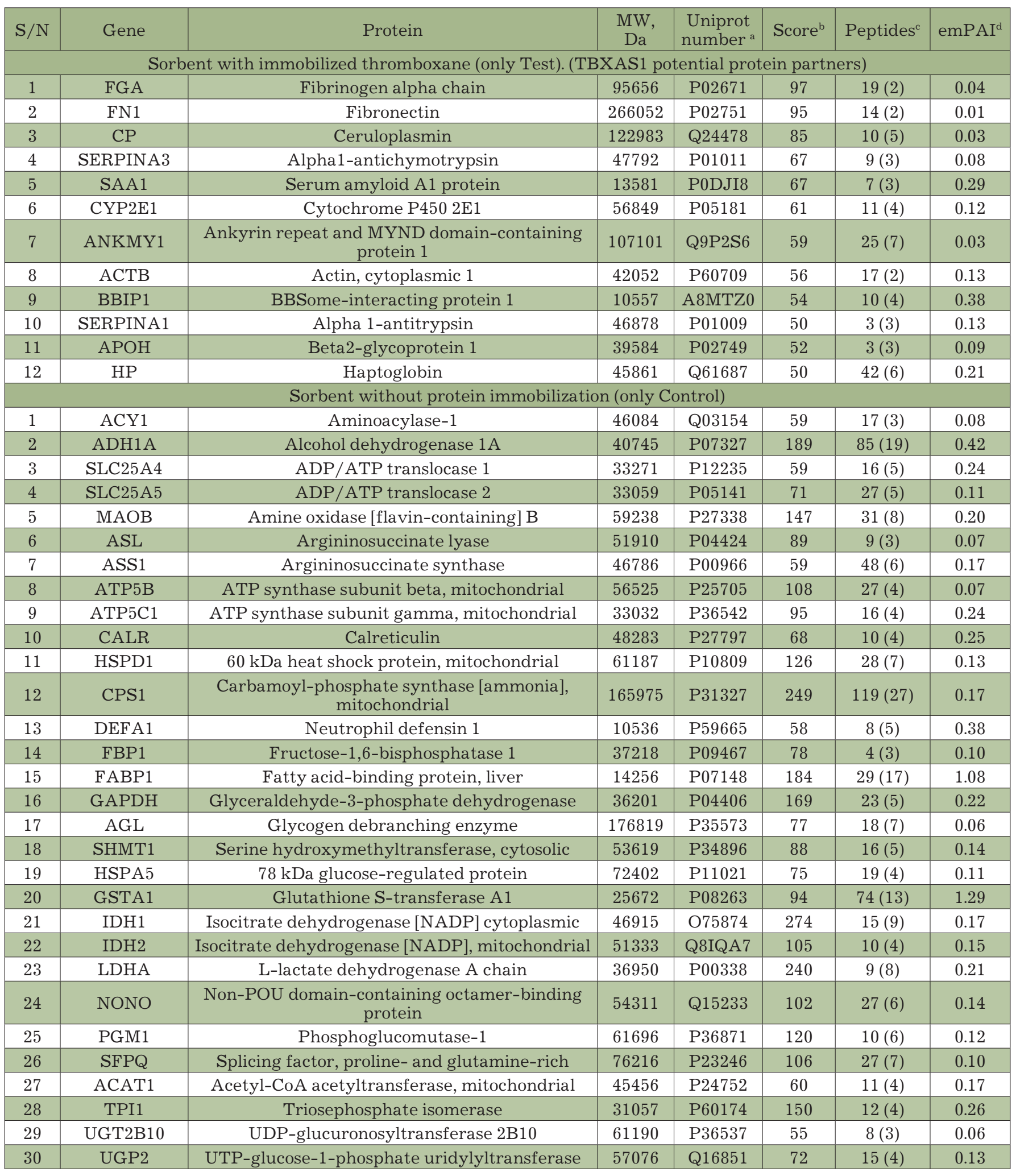




\begin{tabular}{|c|c|c|c|c|c|c|c|}
\hline \multicolumn{8}{|c|}{ Control - upper line, Test - bottom line } \\
\hline 1 & UGP2 & Alcohol dehydrogenase 1B & 40684 & $\mathrm{P} 00325$ & 408 & $117(34)$ & 1.02 \\
\hline & & & & & 90 & $53(6)$ & 0.30 \\
\hline \multirow[t]{2}{*}{2} & $\mathrm{ADH} 4$ & Alcohol dehydrogenase 4 & 41108 & $\mathrm{P} 08319$ & 222 & $36(16)$ & 0.42 \\
\hline & & & & & 85 & $13(8)$ & 0.30 \\
\hline \multirow[t]{2}{*}{3} & ALB & Serum albumin & 71317 & $\mathrm{P} 02768$ & 2790 & $360(150)$ & 1.90 \\
\hline & & & & & 959 & $186(50)$ & 0.66 \\
\hline \multirow[t]{2}{*}{4} & ALDH2 & Aldehyde dehydrogenase, mitochondrial & 56859 & $\mathrm{P} 05091$ & 400 & $33(15)$ & 0.29 \\
\hline & & & & & 94 & $7(3)$ & 0.07 \\
\hline \multirow[t]{2}{*}{5} & ALDOB & Fructose-bisphosphate aldolase B & 39961 & $\mathrm{P} 05062$ & 167 & $25(8)$ & 0.31 \\
\hline & & & & & 220 & 28 (8) & 0.09 \\
\hline \multirow[t]{2}{*}{6} & APOA1 & Apolipoprotein A-I & 30759 & $\mathrm{P} 02647$ & 98 & $12(6)$ & 0.42 \\
\hline & & & & & 53 & $25(6)$ & 0.59 \\
\hline \multirow[t]{2}{*}{7} & ATP5F1 & ATP synthase subunit $b$, mitochondrial & 28947 & P24539 & 192 & $17(10)$ & 0.45 \\
\hline & & & & & 97 & $13(5)$ & 0.28 \\
\hline \multirow[t]{2}{*}{8} & ATP5L & ATP synthase subunit g, mitochondrial & 11421 & O75964 & 265 & $7(6)$ & 0.35 \\
\hline & & & & & 157 & $5(5)$ & 0.35 \\
\hline \multirow[t]{2}{*}{9} & DCXR & L-xylulose reductase & 26182 & Q7Z4W1 & 194 & $27(6)$ & 0.15 \\
\hline & & & & & 161 & $8(5)$ & 0.15 \\
\hline \multirow[t]{2}{*}{10} & DECR1 & 2,4-dienoyl-CoA reductase, mitochondrial & 36330 & Q16698 & 250 & $24(11)$ & 0.22 \\
\hline & & & & & 222 & $13(8)$ & 0.10 \\
\hline \multirow[t]{2}{*}{11} & HSD17B4 & Peroxisomal multifunctional enzyme type 2 & 80092 & P51659 & 1754 & $179(87)$ & 1.26 \\
\hline & & & & & 112 & $16(5)$ & 0.09 \\
\hline \multirow[t]{2}{*}{12} & SORD & Sorbitol dehydrogenase & 38927 & Q00796 & 171 & $17(13)$ & 0.44 \\
\hline & & & & & 73 & $7(4)$ & 0.10 \\
\hline \multirow[t]{2}{*}{13} & CES1 & Liver carboxylesterase 1 & 62766 & P23141 & 88 & $28(4)$ & 0.06 \\
\hline & & & & & 83 & $20(4)$ & 0.06 \\
\hline \multirow[t]{2}{*}{14} & HBA1 & Hemoglobin subunit alpha & 15305 & P69905 & 70 & $48(10)$ & 2.90 \\
\hline & & & & & 82 & $16(6)$ & 0.25 \\
\hline \multirow[t]{2}{*}{15} & HBB & Hemoglobin subunit beta & 16102 & P68871 & 153 & $30(11)$ & 0.54 \\
\hline & & & & & 222 & $29(14)$ & 0.54 \\
\hline \multirow[t]{2}{*}{16} & HMGCS2 & $\begin{array}{l}\text { Hydroxymethylglutaryl-CoA synthase, mito- } \\
\text { chondrial }\end{array}$ & 57113 & P22791 & 249 & $26(13)$ & 0.37 \\
\hline & & & & & 98 & $10(3)$ & 0.07 \\
\hline \multirow[t]{2}{*}{17} & $\mathrm{HRG}$ & Histidine-rich glycoprotein & 60510 & $\mathrm{P} 04196$ & 60 & $14(6)$ & 0.13 \\
\hline & & & & & 52 & $9(5)$ & 0.13 \\
\hline \multirow[t]{2}{*}{18} & PHB2 & Prohibitin-2 & 33276 & Q99623 & 107 & $11(4)$ & 0.11 \\
\hline & & & & & 99 & $7(3)$ & 0.11 \\
\hline \multirow[t]{2}{*}{19} & $\mathrm{ACAA} 2$ & 3-ketoacyl-CoA thiolase, mitochondrial & 42354 & $\mathrm{P} 42765$ & 82 & $20(6)$ & 0.18 \\
\hline & & & & & 71 & $15(3)$ & 0.18 \\
\hline \multirow[t]{2}{*}{20} & $\mathrm{TF}$ & Serotransferrin & 79294 & P02787 & 138 & $20(6)$ & 0.15 \\
\hline & & & & & 142 & $22(7)$ & 0.20 \\
\hline \multirow[t]{2}{*}{21} & SLC25A1 & Tricarboxylate transport protein, mitochondrial & 34333 & P53007 & 70 & $9(4)$ & 0.23 \\
\hline & & & & & 54 & $10(3)$ & 0.23 \\
\hline
\end{tabular}

a - Numbers in the Uniprot database (http: / / www.uniprot.org).

b - The reliability of peptide identification by mass spectrometry (MASCOT score).

c - The number of MASCOT peptides; the number of unique peptides (in parentheses).

d - emPAl, Exponentially Modified Protein Abundance Index.

The names of the identified proteins are listed in the same form as they appear in the Uniprot database used for their identification. 
strates. On the other hand, oligomerization of various cytochromes $\mathrm{P} 450$ can also lead to change in the catalytic parameters of enzymatic reactions: e.g., the affinity of the enzymes to the substrate [33]. Schematic representation of a TXA 2 biosynthesis system complemented by our experimental data is shown in Fig. 1.

We confirmed the formation of the heteromeric TBXAS1 - CYP2E1 complex in direct SPR experiments (Fig. 2). The specificity of the TBXAS1 and CYP2E1 interaction was tested by running control SPR experiments using both microsomal (CYP2C19, CYP3A4, CYP3A5) and mitochondrial (CYP11A1, CYP11B1, CYP11B2) cytochromes P450 as analytes. Other well known cytochrome $\mathrm{P} 450$ protein partners (CYB5A, CPR, ADR, ADX) and several proteins unrelated to the cytochrome $\mathrm{P} 450$ monooxygenase system (FECH, SMAD4, RAB27B, RBP4) were also used for the specificity test. It was shown that all protein analytes, except for CYP11B2 (Fig. 3), did not bind to TBXAS1 immobilized on the optical chip even at micromolar concentrations. A similar control experiment using TBXAS1 as a protein analyte showed no dimerization or oligomerization process. Thus, we can confidently state that the interaction of CYP2E1 and CYP11B2 with TBXAS1 is highly specific.

The calculated $K_{d}$ values of TBXAS1 - CYP11B2 and TBXAS1 - CYP2E1 complex formation were $(6.9 \pm 0.3) \times 10^{-7} \mathrm{M}$ and $(4.3 \pm 0.4) \times 10^{-7} \mathrm{M}$, respectively. These values are comparable to $K_{d}$ of the complexes of various cytochromes $\mathrm{P} 450$ with their functional partners (CPR, CYB5A, ADX) [23, 34-37]. It is important to note that, while the difference in the $K_{\mathrm{d}}$ values of complex formation is about twofold, TBXAS1 - CYP11B2 and TBXAS1 - CYP2E1 interactions are very different in their kinetic parameters. Association and dissociation of TBXAS1 - CYP2E1 occur about an order of magnitude slower compared to TBXAS1 - CYP11B2. Association rate constants $\left(k_{\text {on }}\right)$ are at a 10 -fold difference, and dissociation rate constants of the complexes $\left(k_{\text {off }}\right)$ are at a 15-fold difference.

The revealing of specific TBXAS1 - CYP11B2 complex formation was a new and unexpected result, since CYP11B2 was not identified as a protein partner of TBXAS1 used as a bait in the experiments on molecular fishing from liver tissue lysate (Table). These data are quite comparable, they are not due to the false-negative results of molecular fishing, and can be explained in terms of the tissue-specific CYP11B2 expression profile (preferential expression in the adrenal tissue), which appears from the information in the open Internet resources Proteinatlas (http://www.proteinatlas.org) and Genecards (http://www.genecards.org) and publications [38]. It is currently difficult to deduce the functional consequences and causes of this PPI, so this paper reports only on the fact of experimental confirmation of a direct interaction between TBXAS1 and CYP11B2.

It is known that indole is oxidized to isatin by some cytochromes P450 (CYP2A6, CYP2C19, and CYP2E1) which are responsible for the metabolism of various xenobiotics [18]. Isatin is an endogenous bioregulator with a wide range of biological and pharmacological activities which are implemented when it interacts with many intracellular isatin-binding proteins [1922, 39-41]. Since CYP2E1 turned out to be one of the proteins that interact with TBXAS1, we assumed that isatin can affect TBXAS1 - CYP2E1 complex formation. This hypothesis was tested via SPR analysis of the interaction between TBXAS1 and CYP2E1 in the absence and presence of isatin. We found that isatin really affects TBXAS1 - CYP2E1 complex formation, but it has no effect on the TBXAS1 - CYP11B2 interaction (Fig. 4) used as a control. The effect of the fivefold increase in the affinity of TBXAS1 - CYP2E1 in the presence of isatin is due to both a twofold increase in $k_{\text {on }}$ values and a 2.5 -fold decrease in $k_{\text {off }}$.

\section{CONCLUSION}

TBXAS1 potential protein partners were isolated from a human liver tissue lysate by direct molecular fishing and mass-spectrometric identification. Using the SPR biosensor technique, it was for the first time shown that TBXAS1 interacts with cytochrome P450 CYP2E1 and CYP11B2, while the affinity of TBXAS1 - CYP2E1 complex formation is fivefold higher in the presence of low-molecular-weight nonpeptide endogenous bioregulator isatin (2,3-dioxindole). Overall, our results suggest that TBXAS1 has other functions, such as participation in the functioning of the cytoskeleton and regulation of the biosynthesis of biologically active molecules.

Preparation of recombinant proteins was carried out at the Institute of Bioorganic Chemistry of the Belarusian Academy of Sciences and supported by the Belarusian

Republican Foundation for Fundamental Research (Grant No X16P-062). The studies on molecular fishing and identification of potential TBXAS1 protein partners were carried out at the Institute of Biomedical Chemistry and supported by the Russian Foundation for Basic Research (grant No 16-54-00097 Bel_a), and the study of the effect of isatin on PPI involving

TBXAS1 was supported by the Russian Science

Foundation (grant No 16-14-10327). LC-MS/MS protein identification was performed using equipment from the "Human Proteome" Core Facilities of the Institute of Biomedical Chemistry (Russia) 


\section{REFERENCES}

1. Waterman M.R., Pikuleva I.A. Encyclopedia of Molecular Cell Biology and Molecular Medicine, Weinheim, Germany: Wiley-VCH., 2006. 716 p.

2. Hamberg M., Svensson J., Samuelsson B. // Proc. Natl. Acad. Sci. USA. 1975. V. 72. № 8. P. 2994-2998.

3. Haurand M., Ullrich V. // J. Biol. Chem. 1985. V. 260. P. 15059-15067.

4. Uchida K. // Trends Cardiovasc. Med. 1999. V. 9. № 5. P. 109-113.

5. Chaudhary A.K., Nokubo M., Reddy G.R., Yeola S.N., Morrow J.D., Blair I.A., Marnett L.J. // Science. 1994. V. 265. № 5178. P. 1580-1582.

6. Sadowitz P.D., Setty B.N., Stuart M. // Prostaglandins. 1987. V. 34. № 5. P. 749-763.

7. Ruf A., Mundkowski R., Siegle I., Hofmann U., Patscheke H., Meese C.O. // Br. J. Haematol. 1998. V. 101. № 1. P. 59-65. 8. Shen R.F., Tai H.H. // J. Biol. Chem. 1986. V. 261. № 25. P. 11592-11599.

9. Ullrich V., Nüsing R. // Stroke. 1990. V. 21. № 12 Suppl. P. IV 134-138.

10. Nüsing R., Sauter G., Fehr P., Dürmüller U., Kasper M., Gudat F., Ullrich V. // Virchows Arch. A. Pathol. Anat. Histopathol. 1992. V. 421. № 3. P. 249-254.

11. Huang J.-S., Ramamurthy S.K., Lin X., Le Breton G.C. // Cell. Signal. 2004. V. 16. № 5. P. 521-533.

12. Ivanov A.S., Zgoda V.G., Archakov A.I. // Russ. J. Bioorganic Chem. 2011. V. 37. № 1. P. 4-16.

13. Huttlin E.L., Ting L., Bruckner R.J., Gebreab F., Gygi M.P., Szpyt J., Tam S., Zarraga G., Colby G., Baltier K., et al. // Cell. 2015. V. 162. № 2. P. 425-440.

14. Nathan J.A., Kim H.T., Ting L., Gygi S.P., Goldberg A.L. // EMBO J. 2013. V. 32. № 4. P. 552-565.

15. Ershov P., Mezentsev Y., Gnedenko O., Mukha D., Yantsevich A., Britikov V., Kaluzhskiy L., Yablokov E., Molnar A., Ivanov A., et al. // Proteomics. 2012. V. 12. № 22. P. 32953298.

16. Ivanov A.S., Medvedev A., Ershov P., Molnar A., Mezentsev Y., Yablokov E., Kaluzhsky L., Gnedenko O., Buneeva O., Haidukevich I., et al. // Proteomics. 2014. V. 14. № 20. P. 2261-2274.

17. Ivanov A.S., Ershov P.V., Molnar A.A., Mezentsev Y.V., Kaluzhskiy L.A., Yablokov E.O., Florinskaya A.V., Gnedenko O.V., Medvedev A.E., Kozin S.A., et al. // Russ. J. Bioorganic Chem. 2016. V. 42. № 1. P. 14-21.

18. Gillam E.M., Notley L.M., Cai H., De Voss J.J., Guengerich F.P. // Biochemistry. 2000. V. 39. № 45. P. 13817-13824.

19. Medvedev A.E., Clow A., Sandler M., Glover V. // Biochem. Pharmacol. 1996. V. 52. № 3. P. 385-391.

20. Medvedev A., Igosheva N., Crumeyrolle-Arias M., Glover V. // Stress. 2005. V. 8. № 3. P. 175-183.

21. Medvedev A., Buneeva O., Glover V. // Biologics. 2007.

V. 1. № 2. P. 151-162.
22. Pandeya S.N., Smitha S., Jyoti M., Sridhar S.K. // Acta Pharm. 2005. V. 55. № 1. P. 27-46.

23. Sergeev G.V., Gilep A.A., Usanov S.A. // Biochemistry (Moscow). 2014. V. 79. № 5. P. 406-416.

24. Dormeshkin D.O., Svirid A.V., Gilep A.A., Usanov S.A. // Proceedings of the National Academy of sciences of Belarus. 2015. V. 59. № 2. P. 53-60.

25. Wiśniewski J.R., Zougman A., Nagaraj N., Mann M. //

Nat. Methods. 2009. V. 6. № 5. P. 359-362.

26. Loktev A.V., Zhang Q., Beck J.S., Searby C.C., Scheetz T.E., Bazan J.F., Slusarski D.C., Sheffield V.C., Jackson P.K., Nachury M.V. // Dev. Cell. 2008. V. 15. № 6. P. 854-865.

27. Cerecedo D. // Blood Coagul. Fibrinolysis. 2013. V. 24. P. 798-808.

28. Mosavi L.K., Cammett T.J., Desrosiers D.C., Peng Z. // Protein Sci. 2004. V. 13. № 6. P. 1435-1448.

29. Moussavi-Harami S.F., Annis D.S., Ma W., Berry S.M., Coughlin E.E., Strotman L.N., Maurer L.M., Westphall M.S., Coon J.J., Mosher D.F., et al. // J. Proteome Res. 2013. V. 12. № 7. P. 3393-3404.

30. Pankov R., Yamada K.M. // J. Cell Sci. 2002. V. 115. Pt 20. P. 3861-3863.

31. Lu Y., Cederbaum A.I. // Free Radic. Biol. Med. 2008. V. 44. № 5. P. 723-738.

32. Arnold C., Konkel A., Fischer R., Schunck W.-H. // Pharmacol. Rep. 2010. V. 62. № 3. P. 536-547.

33. Davydov D.R., Davydova N.Y., Sineva E. V, Halpert J.R. // J. Biol. Chem. 2015. V. 290. № 6. P. 3850-3864.

34. Gnedenko O.V., Yablokov E.O., Usanov S.A., Mukha D.V., Sergeev G.V., Bulko T.V., Kuzikov A.V., Moskaleva N.E., Shumyantseva V.V., Ivanov A.S., et al. // Chem. Phys. Lett. 2014. V. 593. P. 40-44.

35. Bridges A., Gruenke L., Chang Y.T., Vakser I.A., Loew G., Waskell L. // J. Biol. Chem. 1998. V. 273. № 27. P. 1703617049.

36. Strushkevich N., MacKenzie F., Cherkesova T., Grabovec I., Usanov S., Park H.-W. // Proc. Natl. Acad. Sci. USA. 2011. V. 108. № 25. P. 10139-10143.

37. Lewis D.F., Hlavica P. // Biochim. Biophys. Acta. 2000. V. 1460. № 2-3. P. 353-374.

38. Fallo F., Pezzi1 V., Barzon L., Mulatero P., Veglio F., Sonino N., Mathis J. M. // Eur. J. Endocrinol. 2002. V. 147. P. 795802.

39. Buneeva O.A., Kopylov A.T., Tikhonova O. V., Zgoda V.G., Medvedev A.E., Archakov A.I. // Biochemistry (Moscow). 2012. V. 77. № 11. P. 1326-1338.

40. Buneeva O., Gnedenko O., Zgoda V., Kopylov A., Glover V., Ivanov A., Medvedev A., Archakov A. // Proteomics. 2010. V. 10. № 1. P. 23-37.

41. Medvedev A.E., Buneeva O.A., Kopylov A.T., Gnedenko O.V., Medvedeva M.V., Kozin S.A., Ivanov A.S., Zgoda V.G., Makarov A.A. // Int. J. Mol. Sci. 2014. V. 16. № 1. P. 476-495. 